\title{
Motion and emotion on the language learning
}

\section{stage}

\section{Umberto Capra}

\begin{abstract}
Growing numbers of teachers and students practicing theatre and drama techniques to boost language learning are convinced of the usefulness for the language learning process of improvising or enacting a script, of reinterpreting or faithfully performing a piece of literary drama. The latest findings in the field of neurosciences give a new and robust scaffolding to teachers' general belief that drama activities boost language learning. It is argued that such expectations are well-rooted in language teaching methodology and that drama, theatre and the performing arts in general do offer a peculiar combination of benefits to foreign and second language learning, as exemplified by: 1) a paradigmatic case of cooperative learning, with naturally inbuilt roles; 2) an authentic reason for repetition and memorization, enriching rote with meaning and expression. Evidence resulting from neuroimaging research and developments of the discovery of mirror neurons and consequent hypotheses about the evolutionary path to the development of verbal language are reviewed to show 'hard science' support to the beliefs gathered through praxis by teachers and students and to direct a specific focus on (the need for) the connection of body, voice, motion and emotion in (language) learning.
\end{abstract}

\section{The stage and the mirror}

Giacomo Rizzolati and Corrado Sinigaglia in So quel che fai. Il cervello che agisce e $i$ neuroni specchio $(2006)^{1}$ explained the role of the mirror neurons in our brains - their paradigm-shattering discovery of the early 1990s to the layperson. They opened their foreword quoting the director and playwright Peter Brook who affirmed that with the discovery of mirror neurons neurosciences started understanding what has always been a very well-known and evident truth to actors and playwrights. This is what Peter Brook said in a speech on The Art of the Present delivered on May 23rd 2005 at Tel Aviv University $^{2}$ :

\footnotetext{
${ }^{1}$ English translation by Frances Anderson as Mirrors in the Brain (2008).

2 What follows is the author's transcript of the conference video (courtesy of Tel Aviv University)
} 
This brings us back to a great new discovery of neurology. But this is very new. Neurology has discovered that there is something called the 'mirror neuron'. That means that in all the circuits of the brain [U+2012] amongst all the many things happening [U+2012] there is something that's moving, a neuron, that they have named the 'mirror'. Now, what does this mean? [It] means that it has now been discovered [U+2012] with very advanced and incredibly expensive instruments [U+2012] that if one human being is sitting watching another human being and the other human being says "Ouch" [left hand goes to cover right eye as for sudden pain], a certain neuron lights up in his brain and the person watching [U+2012] who at this moment is being tested by an enormous magnetic resonance instrument $[U+2012]$ exactly the same neuron lights up in his brain. Which proves that when an actor acts the person watching can participate in his experience [audience laugh]. So you will see how astonishing it is that science has at last proved that acting is ... [P. B. stops and his face expression turns from smiling to very serious] Now, this goes a long way; no, I don't want to take away from this vast and magnificent world of exploration that neurologists are doing, but, on the contrary, to show that they have done to us a great service, in showing that the act of playing something and the act of observing someone who is playing is an enormous act of human participation; that as one person enters more and more deeply into something that comes only from their own deepest subjective experience [U+2012] doing beyond what they think to be the experience into something even further, even deeper [U+2012] there can be an instant recognition, an instant understanding, a shared understanding between everyone who is watching.

Notwithstanding a kind of 'we know better' wink to the audience, Brook refrains from understating the importance of the light shed by neuroimaging and the discoveries of neurosciences on our understanding of fundamental questions like that of (self)consciousness, empathy, interpersonal communication and the development of verbal language.

In this article it will be suggested that the last two decades of discoveries in the field of the neurosciences offer new and robust scaffolding to the belief that drama activities can be extremely beneficial to language learning; a largely shared opinion among all those - teachers, students, drama instructors - even if they have only had occasional experiences of drama activities for language learning. It is a belief, it will be suggested, with sound foundations in language teaching methodology.

\section{Cooperative learning}

One characterizing, positive and essential aspect of drama and the performing arts in general is that they are the result of a cooperative effort of different agents or, if you prefer, actors. Although the prime donne are inevitable, albeit not in the books of rules, one could say that the stage is the field of what, in a sport metaphor, could certainly be defined as a team game. 
Advocates for a cooperative approach to learning can be traced back to Quintilian and Comenius (Coppola et al. 1997: 1) or more recently to Dewey and Cousinet, yet it is in the 1960s and '70s, starting in the United States (Johnson \& Johnson, Slavin) yet with different but as vigorous European experiences, that cooperative learning practices are studied and defined. The key phrases for cooperative learning are positive interdependence and individual accountability. 'Positive interdependence' occurs when students realize that their individual success is inextricably linked to the success of each and every other member of the group; its counterpart is 'individual accountability', that is each group member's individual responsibility and contribution, for her or his part, to the group effort and success. One of the main points in Coppola et al. (1997) is that cooperative learning needs structuring to be effective, and that students working in a group should be given a definite set of roles. 'Positive interdependence', 'individual accountability' and attribution of 'a definite set of roles' fit the players performing on stage as sartorial suits. And roles are naturally inbuilt in the performing arts.

In the 'positive interdependence' setting, errors change their nature and appear in a different light, too. The prime norm reference and evaluator is no longer the teacher, but the audience, and the main individual responsibility is towards one's fellow players, whose collection of individual accountabilities becomes also one's most relevant asset. One of the students taking part in the 2012 edition of our Vercelli Department's TiLLiT ${ }^{3}$ project summed it up in few words (Solinas 2013: 56):

Si crea un legame molto importante con gli altri attori, si forma una vera e propria squadra. Tutti contribuiscono, mettendoci del loro. E quando si vede il risultato concreto, ovvero lo spettacolo finale, la soddisfazione è immensa.

Most of all, playing together can be a lot of fun.

\section{Repetita iuvant?}

Repetition is a vexata quæstio in language teaching: it is seen as a necessary rote to get learners acquainted with foreign sounds, allowing them to gain confidence with novel pronunciation and intonation and memorize language chunks. Yet repeating (similarly to what has happened for memorization) has gained a bad reputation as a boring, mechanical, meaningless routine. The behaviourist

\footnotetext{
3 TiLLiT stands for Teatro in Lingua/ Lingua in Teatro i.e. Theatre in the [Foreign] Language /Language in the Theatre- Since 2004 modern languages students have been experimenting with drama and have brought on stage (adapted) plays or original acts authored through improvisation practice in English, French, German and Spanish. At the beginning of summer the TiLLiT festival offers a showcase and a meeting point for the productions both of the Vercelli students and of guest groups from universities in Italy and abroad (also contributing in Italian as a foreign language). In 2014 TiLLiT was awarded the European Language Label.
} 
approach of the Audio-Lingual Method (a.k.a. the Mim-Mem Method-mimicry and memorization) played an important role in developing such a negative view. Repetition was aimed at automating unthinking responses; both cognition and emotion had to be cut off in a feedback reinforcement of neuronal loops, a form of subliminal hidden persuasion. Cognition and emotion should instead be reintegrated into repetition activities, so that iteration of minimal patterns is substituted by rehearsal of meaningful utterances pronounced with expressive intonation justified by a communicative contextualization: a condition fittingly attained by rehearsing a play or any kind of show, and much more an effective activity than meaninglessly drillling.

"Now that a year has passed since the show, do you still remember chunks, sentences, expressions from the role you played?"

\section{A distanza di un anno dallo spettacolo ricorda ancora spezzoni, frasi o espressioni della sua parte?}

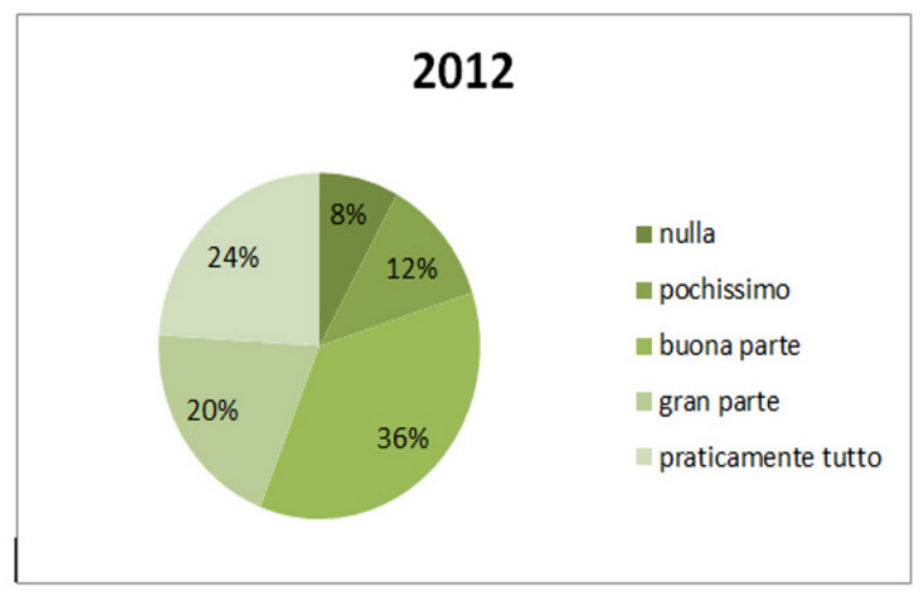

Figure 1: Letizia Solinas, L'apprendimento delle lingue in scena, BA Thesis, Vercelli 2013: 42.

In 2013, Solinas used a questionnaire among TiLLiT students that had been devised and used by Reinhardt (2010: 93ff). To the question "Now that a year has passed since the show, do you still remember chunks, sentences, expressions from the role you played?", only one out of five $(20 \%)$ of the students interviewed answered 'nothing' (8\%) or 'very little" (12\%), while $80 \%$ answered 'a significant part' (36\%), 'most of it' (20\%) or 'practically all' (24\%) (Solinas 2013: 42) (Fig. 1). And 28\% stated they remembered 'a lot' from other players' parts (while 60\% remembered 'something') (ibid. 46) (Fig. 2). Which is even more significant considered that only $50 \%$ of the same target group declared that they remembered chunks, sentences or expressions from the dialogues repeated in language classes (ibid. 44) (Fig. 3). 


\section{"And from other players parts?",}

\section{Ricorda anche parte di testi raccontati da altri?}

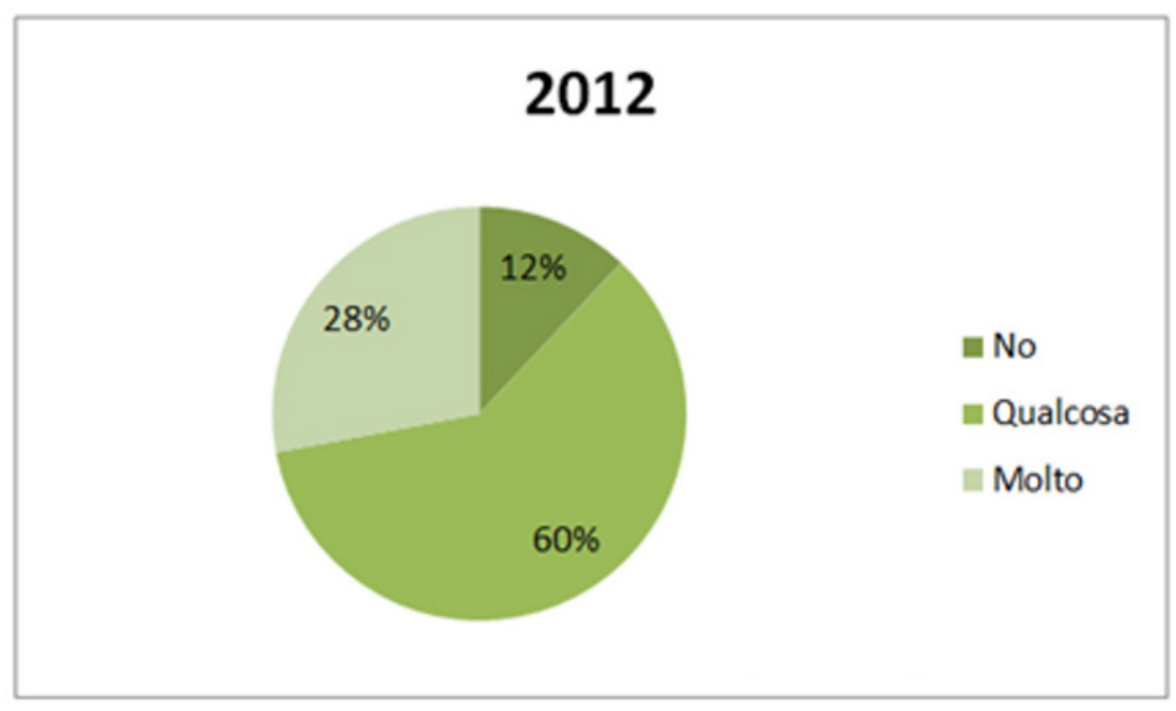

Figure 2: Letizia Solinas, L'apprendimento delle lingue in scena, BA Thesis, Vercelli 2013: 46.

The relevant fact is that acting, playing a dramatic role, even just rehearsing for it, results in much more and much deeper processing than plain repetition. This is surely a statement many language teachers working with drama activities would subscribe to, and which is backed up by mirror neurons and some of the results made available by the neurosciences.

]Mirrors in the brain ${ }^{4}$ Rizzolati and his co-workers in Parma observed neurons in motor areas of the brain spark not only when a subject performed a given action, but also when the subject observed someone else performing that same action. This discovery has caused a revolution in the interpretation of the relationship between perception, motion and cognition, and it has also shed a

\footnotetext{
${ }^{4}$ I must acknowledge the important contribution of a colleague of my same Department, Cristina Meini, whose book Psicologi per natura. Introduzione ai meccanismi cognitivi della psicologia ingenua (2007) with its thorough review and discussion of scientific literature relevant to 'folk psychology', was a precious starting guide. One should not be misled by the deceptive names: there is very little of 'ingenuo' or 'folk' in it: studies in this field deal with understanding consciousness and self-consciousness, the realisation of one's own and others' mental processes, intentions and desires. Such studies align along two main theories: the 'theory of a theory (of mind)' and the 'theory of simulation'. 'Mind reading' is another way of calling it.
} 
"After some time, do you remember chunks, sentences or expressions from the dialogues repeated in language classes?

A distanza di tempo ricorda ancora spezzoni, frasi o espressioni dei dialoghi improvvisati in classe?

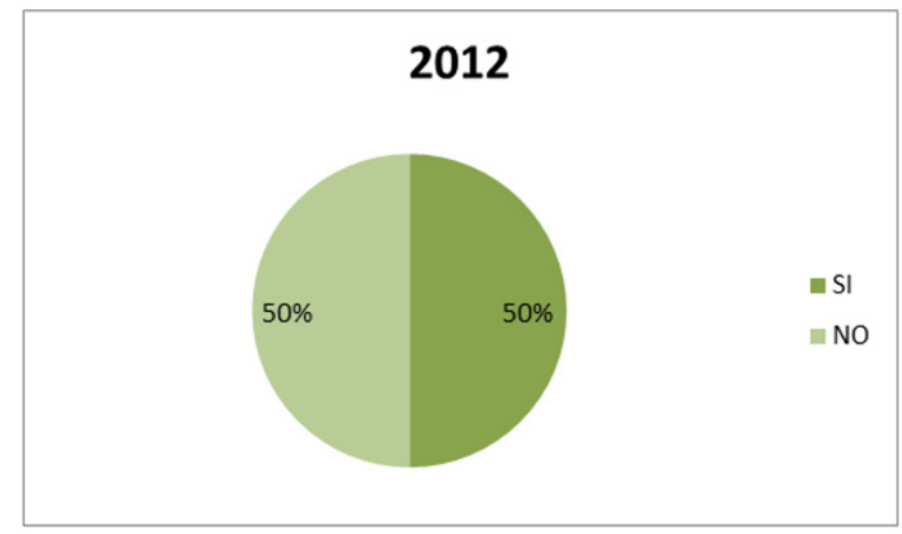

Figure 3: Letizia Solinas, L'apprendimento delle lingue in scena, BA Thesis, Vercelli 2013: 44.

completely new light on how we interpret and share emotions, so much that mirror neurons have also been called 'empathy neurons'.

One of the many seminal results stemming from the discovery of mirror neurons is that their role, directly played according to a 'vocabulary of acts' (vocabolario d'atti) and based on a 'motor knowledge' (conoscenza motoria) (Rizzolati \& Sinigaglia 2006: 122), is that of coding (understanding) the meaning of the actions observed, and, most important, the intentions causing the actions (Iacoboni et al. 2005). These results point to an immediate and intuitive connection to the functional description of language, where functions could be seen fundamentally as actions - verbs - with an intention, a goal: asking the way, giving directions, etc.).

Mirror neurons are probably not the only ones in charge of 'interpreting' body motion and posture. Some neurons interpret eye movement and direction of gaze (Baron-Cohen 1995), while others in the STS (superior temporal sulcus) area are sensible to the position and bending of the head (Hasselmo et al. 1989) ${ }^{5}$. Mirror neurons, though not the only ones sensible to motor signals, seem to be at the centre of the evolutionary process which led to the development of human verbal language.

\footnotetext{
${ }^{5}$ Readers familiar with Jacques Lecoq and his pedagogy of Le corps poétique (1987) will probably see a good reason for his use of la maschera neutra - or le masque neutre - of Amleto Sartori and for the activity in drama courses usually called 'theatre of eyes'.
} 
Steele, Ferrari \& Fogassi (2012) in their introduction to the January Special Issue of The Philosophical Transactions of the Royal Society B, review the studies that

examine tool use and manual gestures in primates as a window on the evolution of the human capacity for language. Neurophysiological research has supported the hypothesis of a close association between some aspects of human action organization and of language representation, in both phonology and semantics. Tool use provides an excellent experimental context to investigate analogies between action organization and linguistic syntax. Contributors report and contextualize experimental evidence from monkeys, great apes, humans and fossil hominins, and consider the nature and the extent of overlaps between the neural representations of tool use, manual gestures and linguistic processes.

\section{Fogassi \& Ferrari (2007: 138f) recall that}

Another category of mirror neurons called "communicative mouth mirror neurons" [...] are specifically activated by the observation of mouthcommunicative gestures belonging to the monkey repertoire, such as slipsmacking, lip protrusion, or tongue protrusion. Interestingly enough, all acts found to be effective in triggering the visual response of these neurons are affiliative acts - that is, friendly gestures with low emotional content - and not threatening or aggressive gestures. [...] The visuomotor response of these neurons seems to reveal the phylogenetic transition from the voluntary control of actions involved in ingestive behavior to that of facial value (Ferrari et al. 2003).

\section{$[\ldots]$}

Summing up, in monkey premotor cortex we observe an integration of several features that can preadapt this area for the evolution of a sophisticated communicative system. The main feature is the encoding of the production and perception of both facial and forelimb actions in the same cortical area. This double control might have been a key function for the subsequent evolution of a coupling between gestures and calls that provided the communicative system with an improved efficiency and a higher level of flexibility in transferring information to other members of the same species. The presence of this coupling is evident in humans and is already visible in apes, as revealed by several observations: a) The gestural repertoire of chimpanzees is often used in association with vocal calls (Corballis, 2003, and commentaries to it in the same issue); b) gestures usually accompany language production; c) sign languages have the same essential properties as spoken language; and d) the execution or observation of hand actions affect both lip opening and sound emission during syllable production of the executing or observing agent, respectively (Gentilucci \& Corballis 2006).

There is a long list of experiments and research showing the correlation mouthhand-voice ${ }^{6}$ via mirror neurons (see Rizzolatti \& Sinigaglia 2006: 153ff), a list

\footnotetext{
${ }^{6}$ Such correlation is likely to support and explain why language teachers have long been
} 
of extreme interest for language teaching and learning based on connecting verbal language, voice, body and motion.

Neuroscientists are telling us that there is wide and coherent experimental and evolutionary evidence that verbal language has developed (and develops) from hand and mouth movements, associated and progressively articulated sounds and the visuomotor response of mirror neurons (so much that a category of them is called "communicative mouth mirror neurons"). The concept of a 'natural process of language acquisition' thus needs to widen its scope beyond the limits of phonology and implicit grammar learning, encompassing body movements and postures and facial expressions. The above quoted review of a large body of research depicts a holistic Language Acquisition Device and it hints at the need for language learning activities integrating oral language, body movement, postures, facial expression and emotions in communication.

\section{Emotion in the mirror}

Mirror neurons have also been called 'empathy neurons': they let us feel what or how another (human) being is feeling. Bastiansen et al. (2009: 2398):

Neuroimaging experiments show that we activate common circuits when observing sensations or emotions felt by others, and when experiencing these sensations and emotions ourselves. This clearly suggests that seeing someone else experiencing touch, disgust or pain triggers much more in us than a purely theoretical, disembodied interpretation of other people's mental states. Witnessing someone experiencing an emotion or a sensation is associated with a pattern of activity in our brain embodying their actions, sensations and affective states.

A resonance is not limited just to pain, fear or disgust. Schippers et al. (2010) let participants in their experiment play the game of charades while they measured brain activity of both gesturer and guesser. They then applied a method to localize direct influences between the brains of the participants (2010: 9388):

Results show that a guesser's brain activity in regions involved in mentalizing and mirroring echoes the temporal structure of a gesturer's brain activity. This provides evidence for resonance theories and indicates a fine-grained temporal interplay between regions involved in motor planning and regions involved in thinking about the mental states of others.

In the last decades there has been an increasing attention to the role of emotions in learning, thus progressively overcoming a traditional view of cognition as a strictly rational process (see for example Von Rhoenek M. et al. 2003). Emotions can be both positive and negative, and it is the negative emotions that are considered as a hindrance to successful learning (Dulay \& Burt 1977).

taught to visualize stress and intonation by "letting the [right] hand move spontaneously" while speaking. 
The language classroom can be a place where students risk losing face. One way to save face is to wear a mask. Wearing a mask (i.e. assuming different pretended identities) and playing roles (together with the use of music and fine arts) have been claimed to lower the so called 'affective filter' (Krashen 1982), to remove any stress from the learning environment, to overcome the emotional barriers that limit students' ability to learn: in a word to 'desuggest' as in Georgi Lozanov's (and Evelyna Gateva's) desuggestopedia (Lozanov 1978; Lozanov \& Gateva 1988). Like many of the so-called Humanistic Approaches, desuggestopedia largely exploits all forms of arts (the performing arts not the least) and it uses them as a key to reach inside the hidden trove of our treasured emotions.

Beard et al. (2007: 235) state that "we need richer conceptions of students as affective and embodied selves and a clearer theorisation of the role of emotion in educational encounters. These areas are currently under-researched and under-theorised in higher education." Eight years later, it is a statement which remains true, strong and difficult to disagree with. The purpose at the core of this article is to point to the theatre as the perfect stage for language students to find the right interplay of body, motion, language and emotion. The cognitive sciences are showing us the sound neurophysiological, evolutionary and functional foundations of such a perspective and at the same time supporting language teaching methodological approaches which are based on it.

In conclusion, a few words borrowed from Amy Cook (2007: 594) may well serve as an epilogue:

The interplay between cognitive science and performance theory provides important information about what Louis Montrose has called the "cognitive and therapeutic instrument" of drama and performance. [...]

How we understand ourselves and our world involves a relationship between body and environment, language and imagination.

Conceptual blending theory illuminates images evoked in the background of a scene that are yet central to the comprehension of the whole scene, a character, or the play.

The brain's reliance on stories - connected with the evidence that these stories can be altered - suggests powerful implications for an art form that uses live bodies to tell stories, that renders visible new worlds, and that animates the seemingly impossible.

\footnotetext{
7 "Suggestopedia is now called Desuggestopedia to reflect the importance placed on desuggesting limitations on learning (Lozanov and [Alison] Miller, personal communication)." (Larsen-Freeman Anderson 2011: 71)
} 


\section{Bibliography}

Baron-Cohen, Simon (1995): Mindblindness: An Essay on Autism and Theory of the Mind. Cambridge, MA: MIT Press

Bastiaansen, Jojanneke C. J.; Thioux, Marc \& Keysers, Christian (2009): Evidence for Mirror Systems in Emotions. In: Philosophical Transactions: Biological Sciences 364/1528, Evolution, Development and Intentional Control of Imitation (August), 2391-2404

Beard, Colin; Clegg, Sue \& Smith, Karen (2007): Acknowledging the Affective in Higher Education. In: British Educational Research Journal 33/2 (April), 235-252

Cook, Amy (2007): Interplay: The Method and Potential of a Cognitive Scientific Approach to Theatre. In: Theatre Journal 59/4, Performance and Cognition (December), 579-594

Coppola, Antonietta; Giuli Graziella \& Invernizzi Franca (1997): Chi ha paura del lavoro di gruppo? Attività in cooperazione per apprendere le lingue straniere. Firenze: La Nuova Italia

Corballis, Michael C. (2003): From Hand to Mouth: The Origins of Language. Princeton, NJ: Princeton University Press

Dulay, Heidi \& Burt, Marina (1977): Remarks on Creativity in Language Acquisition. In: Burt, Marina; Dulay, Heidi \& Finocchiaro, Mary (eds.): Viewpoints on English as a Second Language. New York: Regents

Ferrari, Pier Francesco; Gallese, Vittorio; Rizzolatti, Giacomo \& Fogassi, Leonardo (2003): Mirror neurons responding to the observation of ingestive and communicative mouth actions in the monkey ventral premotor cortex. In: European Journal of Neuroscience 17, 1703-1714

Fogassi, Leonardo \& Ferrari, Pier Francesco (2007): Mirror Neurons and the Evolution of Embodied Language. In: Current Directions in Psychological Science 16/3 (June), 136-141

Gentilucci, Maurizio \& Corballis, Michel C. (2006): From manual gesture to speech: A gradual transition. In: Neuroscience and Biobehavioral Reviews 30, 949-960

Hasselmo, Michael E.; Rolls, Edmund T.; Baylis Gordon C. \& Nalwa, Vanit (1989): Object-Centered Encoding by Face-Selective Neurons in the Cortex of the Superior Temporal Sulcus of the Monkey. In: Experimental Brain Research 3, 179-186

Krashen, Stephen D. (1982): Principles and Practice in Second Language Acquisition. Oxford, UK/Elmsford, NY: Pergamon Press

Iacoboni, Marco; Molnar-Slakacs, Istvan; Gallese, Vittorio; Buccino, Giovanni; Mazziotta, John C. \& Rizzolatti, Giacomo (2005): Grasping the intentions of others with one own's neuron mirror system. In: PLoS Biology 3, 529-535

Larsen-Freeman, Diane \& Anderson, Marti (2011): Techniques \& Principles in Language Teaching. Oxford: Oxford University Press 
Lecoq, Jacques [in collaboration with]; Carasso. Jean-Gabriel \& Lallias, Jean-Claude (1997): Le Corps poétique, un enseignement de la création théâtrale. Anrat: Actes Sud - Papiers

Lozanov, Georgi (1978): Suggestology and Outlines of Suggestopedy. Philadelphia, PA: Gordon \& Breach

Lozanov, Georgi \& Gateva, Evelyna (1988): The Foreign Language Teacher's Suggestopedic Manual. New York: Gordon \& Breach

Meini, Cristina (2007): Psicologi per natura. Introduzione ai meccanismi cognitivi della psicologia ingenua. Roma: Carocci

Rizzolatti, Giacomo \& Sinigaglia, Corrado (2007): Mirrors in the Brain: How Our Minds Share Actions, Emotions, and Experience (transl. Frances Anderson). Oxford: Oxford University Press

Rizzolatti, Giacomo \& Sinigaglia, Corrado (2006): So quel che fai. Il cervello che agisce e i neuroni specchio. Milano: Raffaello Cortina

Reinhardt, Michaela (2010): Theater im universitären Sprachunterricht.„,Alte Methoden" im besonderen Kontext. In: Daf-Werkstatt. Halbjahrszeitschrift für die Didaktik der Deutschen Sprache an der Universität Siena 15-16, 87-96

Schippers, Marleen B.; Roebroeck, Alard; Renken, Remco; Nanetti, Luca; Keysers, Christian; Hari, Riitta (2010): Mapping the information flow from one brain to another during gestural communication. In: Proceedings of the National Academy of Sciences of the United States of America 107/20 (May), 9388-9393

Solinas, Letizia (2013): L'apprendimento delle lingue in scena. Unpublished B.A. thesis. Vercelli: Dipartimento di Studi Umanistici

Steele, James; Ferrari, Pier Francesco \& Fogassi, Leonardo (2012): From action to language: comparative perspectives on primate tool use, gesture and the evolution of human language. In: The Philosophical Transactions of the Royal Society B 367, Special Issue (January), 4-9

Von Rhoneck, Mayring; Von Rhoneck, Philip \& Von Rhoneck, Christoph (eds.) (2003): Learning Emotions: The Influence of Affective Factors on Classroom Learning. Frankfurt a. M.: Peter Lang 